\title{
EDUCAÇÃO AMBIENTAL COMO FERRAMENTA DE AÇÃO NA RECUPERAÇÃO DE ÁREA DEGRADADA EM BONSUCESSO - GUARULHOS
}

\author{
Vanterli Gomes Fialho ${ }^{1}$, Eliane de Siqueira Zanzini \\ ${ }^{1}$ Tecnologista de Gestão Ambiental e Educador Ambiental \\ fialhoeducadorambiental@ig.com.br \\ 2 Professora - Universidade Guarulhos (UnG)
}

\section{RESUMO}

Ao longo da história humana o homem drenou pântanos, cortou árvores, desviou rios, construiu moradias, aldeias, vilarejos, bairros, cidades..., escavaram a procura de minérios, causando grandes impactos na natureza. Este trabalho tem o objetivo de recuperar a área degradada, localizada entre a Estrada das Lavras e a Estrada da Capuava - Guarulhos. Será proposto a recuperação da área degradada, trabalhando com os dados obtidos através do levantamento fotográfico e de campo, atuando nas duas principais variáveis: recuperação física da área degradada e a educação ambiental através de ações realizadas no centro de educação ambiental. Com essas interferências realizadas esperamos que a área se recomponha, e que ao longo de 20 anos os resultados possam ser colhidos por todos, desta forma estaremos promovendo a integração do homem com o meio ambiente, e garantindo a sua utilização equilibrada para as futuras gerações.

\section{ABSTRACT}

Throughout human history man has drained wetlands, cut down forests, diverted rivers, built houses, villages, towns, neighborhoods, cities, ..., dig for minerals, causing major impacts on wild life. This work aims to restore degraded land, located between the Highway and Road Capuava Lavras - Guarulhos. Will be proposed the recovery of degraded areas, working with the data obtained through the photographic survey and field, working in two main variables: physical recovery of degraded areas and environmental education through actions performed in an environmental education center. With such interference carried expect to recompose the area, and over 20 years, the results can be harvested by all, so we will be promoting the integration of man and the environment, and ensuring their balanced use for future generations.

\section{INTRODUÇÃO}

A questão ambiental vem ganhando cada vez mais destaque no mercado global nos últimos anos, isso se deve as fortes evidências científicas (efeito estufa, aquecimento global e escassez dos recursos naturais) sobre as consequências dos impactos da sociedade no ambiente e a necessidade cada vez maior de iniciativas empresariais que possam promover o desenvolvimento sustentável aliado ao desenvolvimento econômico e social, possibilitando a diminuição da degradação à natureza.

A busca por um mundo mais sustentável e ecologicamente correto está fazendo com que governos e demais atores interessados busquem soluções para os problemas que afetam o meio ambiente. 
O município de Guarulhos teve sua origem como elemento de defesa do povoado da Vila de São Paulo de Piratininga, aproximadamente em 1560, com a fundação do aldeamento dos índios Guarus de tribo dos Guaianases, integrantes da nação Tupi, pelo Padre Jesuíta Manuel de Paiva (www.guarulhos.sp.gov.br).

Ao chegarem ao Brasil no início do século XVI os colonizadores portugueses depararam-se com a imensidão verde da densa floresta tropical, com árvores de grande porte e variados extratos. Estavam diante da Mata Tropical Atlântica, que recobria o litoral e áreas interiores dos atuais Rio Grande do Norte até o Rio Grande do Sul, ocupando cerca de 1,3 bilhôes de $\mathrm{Km}^{2}$, e antes da chegada dos europeus, a densidade da ocupação indígena permitia um modo de vida apoiado na caça e coleta não predatórias nessa formação florestal (Giansanti, 1998).

O processo de ocupação das áreas de Mata Atlântica inicia-se com a extração intensiva do pau-brasil, utilizado na tintura e na construção. Posteriormente, os portugueses introduziram lavouras de cana-de-açúcar e cultura de subsistência nos solos férteis da Zona da Mata Nordestina. A derrubada de mata visava dar espaço a monocultura e permitir o suprimento de lenha para os engenhos. Mais tarde, foram introduzidas a mão-de-obra escrava e a pecuária nas áreas onde a mata foi derrubada (Giansanti, 1998).

Seu crescimento econômico deu-se inicialmente em função da mineração de ouro. As minas foram descobertas em 1590 por Afonso Sardinha, localizada na atual região do bairro dos Lavras, cujas antigas denominações eram Serra de Jaguamimbaba, Mantiqueira e Lavras-Velhas-doGeraldo. (www.guarulhos.sp.gov.br)

Em Guarulhos, assim como em outras cidades, em sua maioria da região metropolitana convivemos com inúmeras áreas degradadas, resultantes da exploração dos recursos naturais e do descarte de lixo, de resíduos da construção civil, etc. Além dessas formas de degradação, existe a resultante do processo de mineração. Em meados de 1750, devido o interesse do mercado europeu pelo ouro e pedras preciosas, acentuou-se a mineração na região. Com o esgotamento das minas auríferas, a mineração do ouro, foi sendo substituída gradualmente pela extração de outras matérias-primas, como areia, argila, calcário, pedras, etc, produtos muito empregados na construção civil.

A vocação inicial foi determinante para a construção histórica da cidade, pois essa relação com o meio ambiente fez com que a comunidade local desenvolvesse habilidades a partir do que era oferecido pela natureza. Podemos identificar ciclos econômicos correspondentes ao processo de povoamento e expansão territorial urbana, que são: o Ciclo do Ouro, Ciclo do Tijolo, e o processo de industrialização (Oliveira, 2008).

Um dos pousos de tropeiros mais conhecidos da região leste guarulhense fica na pequena Vila de Bonsucesso, pouso onde se arranchavam os tropeiros em local que era dotado de água (Rio Baquirivu-Guaçu) e vegetação para alimentar os animais, etc. No local confluem a Estrada das Lavras, Estrada velha de Bonsucesso e a Caminho Velho (Oliveira, 2008).

De modo geral, em torno dos pousos de tropeiros formaram-se pequenos povoados dotados com pequeno mercado coberto com folhas de pindoba, uma igreja, uma praça e poucas casas. Algo muito semelhante a Bonsucesso, onde no pequeno largo da praça existem a Igreja de Nossa Senhora de Bonsucesso, construída em taipa de pilão; e a capela de São Benedito, onde há mais de 250 anos é realizada a romaria e a Festa da Carpição. O lugar compõe parte do cenário do ciclo do ouro na cidade (Oliveira, 2008) .

Historicamente, Bonsucesso é a região onde foram desenvolvidas as principais atividades econômicas verificadas em Guarulhos. Os diferentes ciclos de desenvolvimento (a mineração de 
ouro, a agricultura, a extração de areia e a produção de tijolos, a produção em pequenas chácaras e granjas, a extração de lenha, a implantação das primeiras indústrias e o processo de urbanização) trouxeram conseqüências ambientais negativas para a região (Oliveira, 2010).

\section{OBJETIVOS}

Recuperar a área degradada, localizada entre a Estrada das Lavras e a Estrada da Capuava e promover a integração do homem com o meio ambiente recuperado.

Reinserir espécies vegetais nativas para a recuperação do solo;

Melhorar a qualidade do solo e da água encontrada na área;

\section{METODOLOGIA}

O trabalho será desenvolvido através de pesquisa de campo: observação das características do local, levantamento do entorno, mapas, fotografias, a fim de conhecer as necessidades da região em relação a educação, cultura e áreas de lazer já existentes.

Será ofertado também embasamento teórico, consulta a legislação vigente, teses apresentadas relacionadas com o tema escolhido, sites da Internet, etc.

Após o levantamento realizado e com base nas informações teóricas sobre a recuperação de áreas degradadas será elaborada uma proposta para a criação de um centro educacional voltado ao meio ambiente, abordando aspectos relacionados a preservação, pesquisas, integração do homem com a natureza.

Além da criação do centro educacional, haverá em paralelo a recuperação da área degradada com a interrupção imediata dos impactos antrópicos e o resgate da sua condição natural com a inserção de espécies vegetais nativas.

\section{REFERENCIAL TEÓRICO}

\subsection{Impactos Ambientais}

Ao longo do tempo, as sociedades transformaram a natureza. Muitas destas sociedades preferiram ficar atreladas aos preceitos do pensador francês René Descartes que viveu no século $\mathrm{XVI}$, que acreditava que a natureza era um recurso, um bem a ser apropriado pelos homens.

Em lugar dessa filosofia especulativa que se ensina nas escolas, pode-se encontrar uma outra prática pela qual, conhecendo a força e a ação do fogo, da água, do ar, dos astros, dos céus e de todos os outros corpos que nos cercam tão distintamente como conhecemos os diversos misteres de nossos ofícios poderíamos empregá-las da mesma maneira em todos os usos para os quais são próprios e assim nos tornar como senhores e possuidores da natureza" (Descartes,1999).

Agarrado a esse pensamento o homem desenvolveu uma filosofia onde o colocava no centro do mundo e, se a natureza existe, foi criada para servi-lo e atender as suas necessidades. Logo constituindo uma separação, provocando uma oposição entre homem e natureza. 
Ao se opor e interferir na natureza de forma desordenada, o Homem provoca ao meio ambiente danos irreversíveis. Essas ações desenfreadas que são causadas ao meio ambiente, sempre ocasionaram um enorme desequilíbrio na natureza, provocando grandes mudanças, que nem sempre são assimiladas pelo ecossistema, ameaçando a permanência dos sistemas naturais.

Segundo Branco (2006), o impacto ambiental, é pois, uma espécie de "trauma ecológico" que se segue ao choque causado por uma ação ou obra humana em desarmonia com as características e o equilíbrio do meio ambiente. Os impactos ambientais também podem ser oriundos de fenômenos naturais que são causados acidentalmente, como os raios, choques entre meteoros, excesso de chuvas, etc.

O primeiro impacto causado pelo Homem ao meio ambiente, foi através do fogo. Com a criação e domínio do fogo, o Homem passou a interferir de forma ativa na natureza, alterando-a a seu favor. Com a evolução e as habilidades dos seres humanos para desenvolverem novas tecnologias, o homem cada vez mais foi tornando-se independente da natureza, com isso o que se viu foi a ampliação e a diversificação dos impactos.

Com essa visão e pensamento egoísta de explorar a natureza para desenvolvimento de tecnologias para suprir as necessidades da sociedade ao decorrer dos séculos, o que se observou foi evolução do homem, sem estabelecer limites para o uso dos recursos da natureza. Isso demonstra que a humanidade não percebeu ainda que depende da interação com o meio ambiente para sobreviver. Afinal o homem também faz parte da natureza.

\subsection{Desenvolvimento Econômico x Meio Ambiente}

Com o surgimento do capitalismo no século XVIII e XIX, como uma nova forma de acumular riquezas e, a necessidade social de expandir no mercado, a sociedade percebeu que era preciso desenvolver novas tecnologias que fossem capazes de suprir tais necessidades. Foi a partir disso que começou uma nova fase nos processos produtivos: a Revolução Industrial.

A Revolução Industrial consistiu em um conjunto de mudanças tecnológicas com profundo impacto no processo produtivo em nível econômico, social e ambiental. Foi iniciada na Inglaterra em meados do século XVIII, e expandiu-se pelo mundo a partir do século XIX.

A Revolução Industrial é vista como um gerador de desenvolvimento, empregos, conhecimentos e expectativa melhor de vida. Em certo contexto essa afirmativa é correta, pois a revolução conseguiu trazer desenvolvimento econômico e social às populações, além de proporcionar mais conforto aos seres humanos. Mas em contrapartida, o que se viu depois da Revolução Industrial foi o uso cada vez maior dos recursos naturais não-renováveis, sem se preocupar com o meio ambiente, pois o que prevalecia e às vezes ainda prevalece é a crença de que os recursos naturais são inesgotáveis.

Com as novas tecnologias que foram surgindo após a Revolução Industrial, as empresas e a sociedade, segundo Giansanti (1998) passou a exigir em escala cada vez mais ampliada matériasprimas industriais (minerais, derivados de petróleo, madeira, produtos agrícolas, etc), fontes de energia (combustíveis fósseis, hidrelétricas, termoelétricas, nuclear, etc), infra-estrutura de produção e circulação (estradas, portos, redes de água e esgotos, etc), e outros.

Com a industrialização, a sociedade foi se tornando obsessiva por vender, comprar, gastar, ter relações comerciais em geral. Assim, mais indústrias foram surgindo, e com elas veio a poluição, 
contaminando a atmosfera, os rios e o ambiente onde elas se encontravam. Concomitante a isso, com o volume elevado do consumo, os produtos foram sendo inovados, perdendo muito rápido seus valores, o que acabou acarretando em uma grande produção de lixo, contribuindo para a poluição do meio ambiente. As indústrias começaram a produzir em escalas cada vez maiores, e paralelamente a isso, começaram a lançar um volume maior de gases na atmosfera, além de aumentar o desmatamento, extração exagerada, exploração dos recursos minerais, extinção e destruição de habitat, ocupação de terras para criação de gado, erosão, poluição das águas, entre outros impactos.

A busca incessante por capital, levou a uma ocupação desordenada sem precedentes da natureza. O que se viu após a Revolução Industrial foi um antagonismo entre o homem e o meio ambiente, como se a natureza, não fosse essencial para a sobrevivência da espécie.

A relação entre população e os recursos naturais já vem sendo discutida desde o tempo em que Robert Malthus, expôs sua teoria, que muitos chamam de abordagem neomalthusiana, segundo a qual o equilíbrio ambiental apresenta-se como produto do tamanho e crescimento da população, havendo assim, uma relação direta entre crescimento demográfico e pressão sobre recursos naturais. Disso resulta a conclusão imediata da necessidade do controle populacional.

Certamente, não há como negar que o crescimento populacional seja um problema para as questões ambientais. Mas, nessa relação população-meio ambiente, a questão da escolha de modelos de desenvolvimento e de tipos de tecnologia adotado pelos países torna-se fundamental.

\subsection{Evolução das iniciativas relacionadas à degradação ambiental}

Os olhares para o meio ambiente no Brasil começaram a mudar graças a uma tendência mundial, tendo como ponto de referência a Declaração do Meio Ambiente, adotada na Conferência das Nações Unidas, em Estocolmo, em 1972, onde surgia o direito fundamental à preservação do meio ambiente e o direito à vida (Gomes, 2008).

Essa Declaração consagra nos seus primeiro e segundo princípios, que o ser humano tenha direito fundamental à liberdade, à igualdade e uma vida com condições adequadas de sobrevivência, num meio ambiente que permitisse uma vida digna, ou seja, com qualidade de vida, com a finalidade também, de preservar e melhorar o meio ambiente, para as gerações atuais e futuras (Gomes, 2008).

De acordo com o Decreto Federal no 97.632/89, onde define o conceito de degradação ambiental, podemos entendê-la como "processos resultantes de danos ao meio ambiente, pelos quais se perdem ou se reduzem algumas de suas propriedades, tais como a qualidade produtiva dos recursos naturais".

O conceito de área degradada é multidisciplinar, isto é, ele é utilizado em várias frentes do conhecimento. Por conta disso, esse conceito é amplamente interpretado, variando entre utilizado para representar a depredação de uma mata até a exploração de uma área de tal forma que ela perca suas características de solo e vegetação, podendo culminar até mesmo em uma modificação de relevo.

Dessa forma entende-se por área degradada toda área que, por ação natural ou antrópica teve suas características originais alteradas além do limite de recuperação natural dos solos, exigindo, assim, a intervenção do homem para sua recuperação (Noffs, 2000). 
Em áreas degradadas, oriundas de processos de mineração, e de certa forma é o caso da área em estudo, pois é resultado da exploração de areia, Noffs (2000), ratifica: os fatores mais expressivos da erosão são as escavações, cortes e aterros, provocados por minerações de argila, areia e cascalho, abertura de estradas, expansão urbana e implantação de novos loteamentos, etc., e executados sem a implementação correta de sistemas de proteção aos solos expostos, tais como obras de drenagem, recobrimento vegetal, abatimento de taludes, etc. Nesses casos, pela ação das enxurradas, a erosão é particularmente desastrosa, provocando a formação acelerada de ravinas, e, muitas vezes, de boçorocas, implincando na remoção de volumes consideráveis de solos, entulhando as depressões e assoreando os corpos d'água".

O mérito do Relatório Brundtland está na identificação das linhas gerais para um diagnóstico da crise social e ambiental em escala global e na valorização de princípios como a democracia, a igualdade racial e um sistema internacional de trocas mais equitativo. Entretanto, é preciso examinar cuidadosamente os limites desse conceito e as condições políticas, econômicas e sociais existentes para colocar em prática seus princípios. Nesses limites e condições é possível discutir as perspectivas apontadas pelo desenvolvimento sustentável (Giasanti, 1998).

\subsubsection{Contexto $x$ Conceito da degradação ambiental}

Nascimento et al. (2001) estudam a degradação ambiental a partir de uma abordagem sistêmica, na busca do entendimento da totalidade integrada por meio da conexão das relações e do contexto. Esta abordagem contribui ao entendimento da dinâmica da degradação ambiental, e parte do conhecimento desta dinâmica para tentar resolver o problema por dois caminhos: uma solução sintomática, com ações de curto prazo para diminuir os efeitos da degradação; ou uma solução que observe o longo prazo, visto que as ações problemáticas continuarão a acontecer e contribuir para o aumento da degradação.

Soluções sintomáticas para diminuir a degradação tendem a negligenciar a interconexão dos elementos e a buscar resultados "paliativos", pois ao se preocupar com a aparência perde-se grande parte da essência das relações ambientais (Da Silva, 2005).

O termo degradação se contrapõe ao termo sustentável, que segundo (Giansanti, 1998) remete-nos à idéia daquilo que se pode sustentar. Advindo das ciências naturais, diz respeito do ponto de vista ecológico, à "tendência dos ecossistemas à estabilidade, ao equilíbrio dinâmico, a funcionarem na base da interdependência e da complementariedade, reciclando matérias e energias". Sugere estabilidade e equilíbrio e transmite a idéia de durável por longos períodos de tempo.

Ainda, segundo (Giansanti, 1998), a garantia de sustentabilidade do patrimônio natural, aliada a um desenvolvimento econômico e social pleno, supõe muitos desafios. O primeiro, o de abandonar a ilusão de que se deve atingir antes um crescimento econômico rápido para depois repartir a riqueza social, uma vez que políticas de distribuição de renda e expansão do bem estar condicionam-se, entre outros fatores, ao jogo de forças dos agentes sociais. Segundo, implica a negociação de regras universais de uso sustentável dos recursos naturais, além de exigir a adoção de uma posição de força por parte dos países pobres nas relações econômicas internacionais. Remete, portanto, a um exame crítico da noção de necessidade e dos padrões de consumo atuais, revendo as finalidades da produção econômica e os valores sociais predominantes, o que envolve também atitudes individuais. 
A expansão de um modelo de consumo mundial força a pressão sobre os recursos naturais. Estamos muito longe de nos preocuparmos apenas com o comer, o vestir e o ter onde morar, embora milhões de indivíduos nem isso tenha assegurado. Multiplicam-se de forma permanente e consistente os bens de consumo da era da microeletrônica, como televisores, vídeo-cassetes, computadores, automóveis, etc; e amplia-se o desejo de ter acesso a esses produtos, independentemente da inserção sócio-econômica (embora seja possível diferenciar o consumo dos ricos do consumo dos pobres). De outro lado a produção está cada vez mais voltada para o consumo verticalizado, ou seja, multiplicam-se os tipos de bens disponíveis para o consumo visando atender os segmentos de média e alta renda (Giansanti, 1998).

\section{CARACTERÍSTICAS DA ÁREA DE ESTUDO}

Em visita à região de Bonsucesso, constatamos que a área possui $245.000,00 \mathrm{~m}^{2}$, no qual estão inseridas duas lagoas com $71.500,00 \mathrm{~m}^{2}$, remanescentes de antigas atividades mineradoras; pelo terreno ainda passa o Córrego Araçaú. Apresenta as características desordenadas: ocupação desordenada por moradias e submoradias, esgoto à céu aberto em direção ao córrego, falta de coleta de lixo regular, pois as construções ocasionaram vielas estreitas que não permitem a entrada do caminhão coletor. E em virtude disso, muitos moradores jogam o seu "lixo" diretamente no córrego, locais onde moradores e não-moradores descartam todo tipo de lixo, por exemplo: móveis velhos, entulho, pneus e carcaça de veículos, animais mortos, etc, vários locais apresentam queima de lixo prejudicando a vegetação, ao longo da avenida, podemos observar algumas áreas com vegetação arbustiva e plantas de pequeno porte, trechos do Rio Baquirivú-Guaçu com assoreamento e alargamento do leito do rio, depósito de caminhões, carrocerias, paletes de madeira, etc, destacamos que o local oferece risco em relação à segurança das pessoas, o solo tem características de várzea, com exceção de alguns locais, pois avistamos algumas moradias populares, encontramos duas grandes lagoas, provenientes de cava de extração de areia abandonada, interligadas com suas águas provenientes da água da chuva, mas recebe também outras águas contaminadas por esgotos, lixos, etc, que são um atrativo natural, é comum encontrar pessoas descansando e usufruindo do espaço ao redor da lagoa, para pescar, assar peixes, beber, etc, também existe a criação de gado, que pasta na área e bebe água da lagoa, encontramos a ocorrência de muitas conchas de caramujos com aproximadamente $10 \mathrm{~cm}$, próximo as áreas de várzea detectamos pegadas de animais silvestres, na observação das lagoas, encontramos bastante lixo, como garrafas, plásticos, isopor, caixa de água de amianto, carcaças de animais, entrada de esgoto, através de um córrego que vem da Estrada do Mato das Cobras, proveniente da região do Ponte Alta, carregando todo tipo de sujeira, como garrafas pets, sacos de lixo, madeiras, etc, limítrofe a essa área existe uma ocupação irregular denominada Anita Garibaldi que faz fundos com a área objeto do estudo.

\section{A EDUCAÇÃO AMBIENTAL COMO FERRAMENTA DE AÇÃO}

Uma das questões que geralmente são relacionadas à problemática ambiental tratada no meio educacional, refere-se aos problemas cujo enfoque é tratado apenas no momento em que algo não está bem ou quando existe uma real ameaça ao meio ambiente. As questões de 
preservação e conscientização ambiental devem ser tratadas de maneira contínuas, transdisciplinar, inseridas em todas as falas necessárias pelos educadores.

Não podemos pensar na conservação ambiental de modo utilitário, isto é, na maneira de preservar o meio ambiente com o intuito de usufruir intensamente deste recurso no futuro e, muito menos por romantismo ecológico, Algo como "não destruir o que é belo, porque é natural". Devemos preservar e educar pelo fato de fazermos parte da cadeia, do fluxo e dos elos de interdependência.

A educação ambiental é uma alternativa que tem como proposta resgatar valores éticos, estéticos, democráticos e humanistas, visando modificar as relações entre as pessoas e a natureza, a fim de melhorar a qualidade de vida. Propõe uma transformação do sistema de produção e consumo em uma sociedade baseada na solidariedade, afetividade e cooperação, ou seja, visando a justa distribuição de seus recursos.

É plenamente possível o exercício da cidadania ambiental e da sustentabilidade a partir de um processo pedagógico. No entanto, para que se efetive é necessário compreender o significado do ato de promover a aprendizagem a partir da vida; do cotidiano, a fim de que se possa ensinar e aprender resgatando a sensibilidade, a intuição, as emoções, etc. O propósito da ecopedagocia é educar para a vida planetária, onde a população possa "entender e exigir os seus direitos e exercer suas responsabilidades"

È necessário a construção de uma cidadania que seja consciente e que principalmente assuma e viva as responsabilidades cabíveis para um meio ambiente ecologicamente equilibrado. A cidadania ambiental compreende em inúmeras obrigações não somente com a comunidade, mas principalmente com a preservação e conservação dos recursos naturais do ecossistema planetário.

Para o educador Paulo Freire (1996), ensinar não é transferir somente conhecimento, mas sim criar as possibilidades para a sua produção ou construção. Freire não aceitava a idéia de que o ensinar era transmitir o saber, pois a missão de um educador é muito mais que possibilitar a criação do conhecimento e sim poder levar aos educandos a possibilidade de conhecer.

Cabe a nós educadores, refletirmos sobre as propostas e planejamentos que poderão ser possíveis e compartilhadas no processo de ensino. Paulo Freire sempre enfatizou em suas falas que é necessário a busca constante do saber, pela pesquisa e acima de tudo ter determinação para abraçar qualquer causa que venha a ser abordada em questões de ensino. Para Freire, "ação e reflexão, de tal forma solidárias, ainda que em parte, uma delas, se ressente, imediatamente a outra.

Paulo Freire acreditava que seria possível compreender a situação da sociedade, desde cada um atuasse a favor de um mundo melhor, mais fraterno e igualitário. Isso é possível ? Acreditamos que sim.

Em nossa existência temos que optar por caminhos, por escolhas. Porém, a neutralidade predomina na maioria das vezes, onde as pessoas preferem ficar em posições neutras para decisões políticas ou até mesmo pedagógicas, e isso infelizmente fracassa qualquer decisão que seja determinadora para mudanças. Diariamente nos deparamos por inúmeros desafios, principalmente no meio escolar e acadêmico, e geralmente o que falta é determinação e coragem para abraçar essa causa.

A educação tanto no ensino formal como no informal, é um meio viável e favorável para despertar novas formas de emancipação. Para entendermos a problemática ambiental contemporânea, é necessário entendermos o percurso histórico da relação do homem com a natureza, Desta forma a cidadania aparece como o primeiro desafio, na tentativa de resgatar 
valores humanos. Educar é preciso, pois visa um processo de reflexão dentro de uma sociedade que esta em constantes transformações. Um exemplo de transformação global é a crise ambiental que vivemos nesse inicio de século, causando um verdadeiro impacto na sociedade. A escola tem uma responsabilidade fundamental neste processo, não criando uma disciplina que aborde questões sobre o meio ambiente e cidadania, mas que esteja transversalmente ao longo de todo o currículo e ser trabalhado das mais diversas formas em cada uma das disciplinar sempre que a situação seja propicia.

Portanto, é através de uma educação engajada, eticamente comprometida com as questões ambientais e acima de tudo transformadora, o ser humano vem a ser um instrumento de harmonia planetária, a partir de pequenas ações a atitudes a curto prazo, até chegar a longo prazo, à posturas desafiantes e libertadoras.

É preciso urgentemente pensar o meio acadêmico, as relações ecossistêmicas do meio ambiente, a fim de aprender, educar e conscientizar.

Na criação da estratégia para a participação da comunidade local, esta poderá ser realizada de várias formas:

- desde uma atividade remunerada na própria recuperação da área: movimentação do solo, plantio de mudas e sementes, irrigação, construção de cercas, portarias, etc;

- garantir à comunidade local a participação em cursos no centro de Educação Ambiental, visando o crescimento da consciência ambiental.

\section{PROPOSTA DE TRABALHO}

Após a implantação do projeto e conforme as fases forem sendo executadas, cabe também estabelecer parceria entre o poder público e estabelecimentos de ensino, para o Centro de Educação Ambiental, que deverá ter garantida algumas ações:

a) visitas monitoradas por educador ambiental:

- a um cenário de área degradada resultante da escavação para a retirada de areia e/ou minérios, e resultante do descuido em descartar resíduos em local inapropriado;

- a área de preservação permanente, destacando o potencial da natureza quando ela é preservada;

b) criação de acervo próprio sobre a recuperação da área, mostrando o antes e o depois, acompanhamento das espécies vegetais, sua adaptação e os seus benefícios, acompanhamento da melhora em número e espécies da fauna que voltaram a se estabelecer na área, acompanhamento da qualidade da água, etc.

c) oferecer cursos livres visando aproximar as pessoas dos benefícios gerados pelo meio ambiente;

d) reservar área para atividades de lazer, como por exemplo, pista para caminhada e corrida, playground para crianças, locais para contemplação da natureza; 


\section{CONSIDERAÇÕES FINAIS}

Hoje supera-se a fase eminentemente ambientalista do ecologismo para se adentrar em conteúdos políticos mais explícitos. A busca de condutas ecológicas globais canaliza-se cada vez mais para questões sociais. Parece não haver dúvidas de que os pobres e excluídos são os mais afetados pela degradação ambiental. Essa constatação reforça o diagnóstico de que, para resolver a degradação ambiental, deve-se reverter o quadro de acumulação e distribuição desigual de riquezas (Giansanti, 1998).

É possível o exercício da cidadania ambiental e da sustentabilidade a partir do processo pedagógico. O propósito da ecopedagogia é educar para a vida planetária, onde a população possa entender e exigir os seus direitos e exercer suas responsabilidades. A educação além de ensinar o conhecimento científico, ela deverá preparar as pessoas para o exercício da cidadania. A educação para a cidadania pretende fazer de cada pessoa um agente de transformação. E para que isso se torne possível é necessário informá-lo sobre as diferentes áreas do conhecimento, inclusive através dos direitos e deveres.

\section{REFERÊNCIAS}

BRANCO, Samuel Murgel. O meio ambiente em debate. 3. ed. São Paulo: Moderna, 2006

DA SILVA, Eva de Fátima Grêlo. Análise da implementação dos planos de recuperação de áreas degradadas pela mineração em Lourenço (AP) . Dissertação de Mestrado. PLADES / NAEA / UFPA. Belém, 2005.

DESCARTES. Discurso do método. (Coleção Os Pensadores). São Paulo: Nova Cultural, 1999.

FREIRE, Paulo. Pedagogia da Autonomia: saberes necessários à prática educativa. São Paulo: Paz e Terra, 1996.

GIANSANTI, Roberto. O Desafio do Desenvolvimento Sustentável. 6. ed. São Paulo, 1998.

GOMES, Alessandro. Legislação Ambiental e Direito: um olhar sobre o Artigo 225 da Constituição da

República Federativa do Brasil. Revista Científica Eletrônica de Administração - Garça/S.Paulo. Ano VIII Número 14 - Junho de 2008. Periódicos Semestral.

NOFFS, Paulo da Silva, GALLI, Luiz Fernando e GONÇALVES, Jânio Carlos. Recuperação de Áreas Degradadas da Mata Atlântica. Uma experiência da CESP - Companhia Energética da São Paulo. Caderno no 3 - Série Recuperação. Conselho Nacional da Reserva da Biosfera da Mata Atlântica, 2000.

OLIVEIRA, Elton Soares de., FERNANDES, Maria Claudia Vieira., CARVALHO, Gláucia Garcia de., OMAR, Elmi El Hage., PRÉZIA, Benedito Antonio Genofre., SATO, Sandra Emi., et al. Guarulhos: espaço de muitos povos. - 2a ed. - São Paulo: Noovha América, 2008. - (Série conto, canto e encanto com a minha história...). www.guarulhos.sp.gov.br (Acesso em: 28 junho 2010) 